\title{
In-silico Molecular Docking Studies of some Isolated Phytochemicals from Biophytum veldkampii against Cyclooxygenase-II Enzyme and in vivo Anti-inflammatory Activity
}

\author{
Nagaraju Bandaru1,*, D.S.N.B.K Prasanth' ${ }^{1}$, A.Rajasekhar Reddy², G.S.N Koteswara Rao ${ }^{3}$, Kumar V.S Nemmani ${ }^{4}$, \\ Alla Narayana Rao ${ }^{1}$
}

\section{Nagaraju Bandaru ${ }^{1, *}$, D.S.N.B.K. Prasanth", A.Rajasekhar Reddy ${ }^{2}$, G.S.N Koteswara Rao ${ }^{3}$, Kumar V.S Nemmani ${ }^{4}$ Alla Narayana Rao ${ }^{1}$}

'Department of Pharmacology, College of Pharmacy, Koneru Lakshmaiah Education Foundation, Vaddesweram, Andhra Pradesh, INDIA.

2Department of Pharmaceutical Chemistry, College of Pharmacy, Koneru Lakshmaiah Education Foundation, Vaddesweram, Andhra Pradesh, INDIA. ${ }^{3}$ Department of Pharmaceutics, College of Pharmacy, Koneru Lakshmaiah Education Foundation, Vaddesweram, Andhra Pradesh, INDIA.

${ }^{4}$ Department of Pharmacology, Shri Vishnu College of Pharmacy, Bhimavaram, Andhra Pradesh, INDIA.

Correspondence

Mr. Nagaraju Bandaru

College of Pharmacy, Koneru Lakshmaiah Education Foundation, Vaddesweram, Andhra Pradesh, INDIA.

Phone no: +919603674173

Email id: bnrajupharma@gmail.com

History

- Submission Date: 31-07-2021;

- Review completed: 16-08-2021;

- Accepted Date: 01-10-2021

DOI : 10.5530/pres.13.4.11

Article Available online

http://www.phcogres.com

Copyright

(C) 2021 Phcog.Net. This is an openaccess article distributed under the terms of the Creative Commons Attribution 4.0 International license.

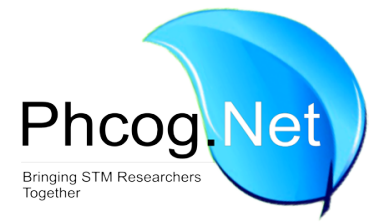

\begin{abstract}
Background: The current study estimate the anti-inflammatory activity of whole plant of Biophytum veldkampii on carageenan induced inflammation on rats compiled by molecular docking studies of phytocompounds from the plants with Cyclooxygenase II (PDB ID: 3LN1). Methods: In this research Biophytum veldkampii was subjected to extraction using methanol. In-vivo anti-inflammatory activity was assessed by using carageenan induced inflammation on rats and in-silico molecular docking studies was performed by using of Autodock 4.0. Results: The outcomes revealed that the methanolic extract has most prominenant anti-inflammatory activity at various doses. Among all the substances 2,6,3',4'-Tetrahydroxy-2-benzylcoumaranone revealed the most effective docking rating of -6.8 , which is near to Diclofenac, i.e. - 6.9, ensuring that 2,6,3',4'-Tetrahydroxy-2-benzylcoumaranone has a strong binding fondness in between protein and ligand. Conclusion: From the results, a conclusion can be drawn that the anti-inflammatory activity of Biophytum veldkampii in both in vivo and in silico methods. This information sustains 2,6,3',4'-Tetrahydroxy-2-benzylcoumaranone to be a useful antiinflammatory compound beneficial to future clinical studies.

Key words: In-silico, Autodock4.0, Carageenan,2,6,3',4'-Tetrahydroxy-2 benzylcoumaranone, Inflammation, Cyclooxygenase II, Phytochemical.
\end{abstract}

\section{INTRODUCTION}

Medicinal plants are a source of valuable therapeutic assistance for the alleviation of human diseases. According to the World Health Organization (WHO), more than 80 per cent of the world's population, mainly in developing countries, relies on conventional plantbased medicines for their primary health needs. ${ }^{[1]}$ Scientific confirmation concerns the screening of bioactive compounds from plants and has contributed to the creation of new medicines with successful roles in the defence and treatment of various diseases. Inflammation is the local reaction of living mammalian tissue to injury. It is a body's immune reaction to eliminate or limit the spread of the injurious agent. There are various components of an inflammatory reaction which may lead to the associated symptoms and tissue injury. Edema, leukocyte infiltration, and granuloma formation are all components of inflammation. It's a defence mechanism, though. Complex events and mediators involved in an inflammatory reaction can cause or aggravate a variety of reactions. ${ }^{[2]}$ Nonsteroidal anti-inflammatory drugs (NSAIDs) are potent antiinflammatory agents acting by inhibition of the enzyme Cyclooxygenase (COX) and subsequent inhibition of prostaglandins at the site of inflammation.
Unfortunately, inhibition of gastrointestinal or renal prostaglandins is associated with mechanism-based sensitivity,that decreases the usefulness of these otherwise powerful and efficient drugs. ${ }^{[3]}$ Two forms of COX enzyme have recently been identified: COX-1, which is constitutively expressed in many cells and tissues, and COX-2, which is selectively induced by proinflammatory cytokines at the site of inflammation. ${ }^{[4]}$ The discovery of a second COX enzyme related to the hypothesis that the toxicity associated with clinically valuable NSAIDs was caused by inhibition of COX-1, while COX-1 was inhibited. In support of this assumption, the expression of the inducible COX-2 enzyme is selectively inhibited by the potent anti-inflammatory drug dexamethasone. Selective inhibition of COX-2 can produce superior anti-inflammatory drugs with considerable safety over existing NSAIDs. ${ }^{[5]}$

Biophytum veldkampii looks like a miniature palm and is native to India. The plants are usually found in wet lands (mostly plains) of tropical Africa, Asia and India, normally in the shades of trees and shrubs, in grasslands, open thickets, at low and medium altitudes. $^{[6]}$
Cite this article: Bandaru N, Prasanth DSNBK, Reddy AR, Rao SNK, Nemmani KVS. In-silico Molecular Docking Studies of some Isolated Phytochemicals from Biophytum Veldkampii against Cyclooxygenase-II Enzyme and in vivo Anti-inflammatory Activity. Pharmacog Res. 2021;13(4):192-8. 
The molecular docking process predicts ligand confirmation and orientation within the targeted binding site which holds great promise in the field of computer-based drug design. ${ }^{[7]}$

In present study we focus on the in silico docking studies of phytochemicals present in Biophytum veldkampii against cyclooxygenase-2 enzyme

\section{MATERIALS AND METHODS}

\section{Plant material}

Biophytum veldkampii whole plants were collected from the forest area of Rampachowdavaram, East Godavari and authenticated by Dr. P. Prasanna Kumari, Botany department, Dantuluri Narayana Raju College, Bhimavaram. A voucher specimen was kept at Pharmacology department, Shri Vishnu College of Pharmacy.

\section{Preparation of plant extract}

The whole plant was dried at room temperature. For removal of waste or fatty materials, the powder is extracted with petroleum ether for 7 days. Now the defatted marc is extracted with methanol by using soxhlet apparatus to get methanolic extract. This extract was dried under reduced pressure; brownish color of extract was obtained. ${ }^{[8]}$ This extract was stored in desecrator for further use.

\section{Phytochemical analysis}

The methanolic extract was subjected to estimation of different phytochemicals as per literature. ${ }^{[9]}$

\section{In vitro COX II inhibition assay}

The assay was performed by using Colorimetric COX (human ovine) inhibitor Screening assay kit. Briefly, the reaction mixture contains, $150 \mu$ of assay buffer, $10 \mu \mathrm{l}$ of heme, $10 \mu \mathrm{l}$ of enzyme (either COX-1 or COX-2), and $10 \mu \mathrm{l}$ of plant sample $(1 \mathrm{mg} / \mathrm{ml})$. The assay utilizes the peroxidase component of the COX catalytic domain. The peroxidase activity was assayed colorimetrically by monitoring the appearance of oxidized N, N, N, N'-tetramethyl-p-phenylenediamine (TMPD) at $590 \mathrm{~nm}$. Diclofenac sodium $1 \mathrm{mM}$ was used as a standard drug. The percent COX inhibition was calculated using following equation: ${ }^{[10]}$

\section{COX II Inhibition activity $(\%)=1-\mathrm{T} / \mathrm{G}^{\star} 100$}

Where $\mathrm{T}=$ Absorbance of the inhibitor well at $590 \mathrm{~nm}$.

$\mathrm{C}=$ Absorbance of the $100 \%$ initial activity without inhibitor well at $590 \mathrm{~nm}$.

\section{Animals}

In this study male Wistar rats were used, animals were kept in animals house and maintained under standard quality conditions (RH 44-56\%, temperature $27 \pm 2^{\circ} \mathrm{C}$ ) and feed with standard diet and drinking water ad libitum for 1 week before and during study. Protocol of this study was approved by IAEC of Shri Vishnu college of Pharmacy and with the permission from CPCSEA Reg No. 439/PO/01/a/CPCSEA.

\section{Assessment of anti-inflammatory activity Carageenan-induced paw edema}

The anti-inflammatory activity of MEBV was assessed in rats using carrageen-induced paw edema model as per the previously described method. ${ }^{[11]}$ Carageenan suspension $(0.1 \mathrm{ml}$ of $1 \% \mathrm{w} / \mathrm{v}$ in normal saline) was injected into the sub-plantar region of right hind paw. Total 25 rats were randomly divided into 5 groups each containing 5 rats. Rats were pretreated with vehicle or MEBV (400 and $200 \mathrm{mg} / \mathrm{kg}$, orally) or reference standard Diclofenac $(70 / \mathrm{mg} / \mathrm{kg})$ at $1 \mathrm{~h}$ earlier to carageenan injection.
The paw volume at $0 \mathrm{~h}, 3 \mathrm{~h}, 5 \mathrm{~h}$ and $24 \mathrm{hr}$. After carageenan administration was measured in ml using Plethysmometer (Ugo Basile, Italy).

\section{Formalin induced Inflammation}

MEBV was assessed for evaluation of anti-inflammatory activity in formalin induced inflammation rat model. ${ }^{[12]}$ Total 25 rats were randomly divided into 5 groups each containing 5 rats. After $1 \mathrm{~h}$ orally pretreated rats with vehicle ( $4 \%$ gum acacia) or MEBV (400 and $200 \mathrm{mg} / \mathrm{kg}$ ) or Diclofenac $(70 \mathrm{mg} / \mathrm{kg})$ intraperitoneal administration of $0.05 \mathrm{ml}$ of $2.5 \%$ commercially available $37 \%$ formalin in dorsal surface of left hind paw in rats. The paw volume at $0 \mathrm{~h}, 3 \mathrm{~h}, 5 \mathrm{~h}$ and $24 \mathrm{hr}$. After carageenan administration was measured in $\mathrm{ml}$ using Plethysmometer (Ugo Basile, Italy).

\section{Motility Test}

The motility pattern of the rats was observed for a period of $5 \mathrm{~min}$. If the rat was avoided touching the floor and walked difficulty, score is 0 , if the rat walked with little difficulty but with toe touching the floor, score is 1 and if the rat walked easily score is $2 \cdot{ }^{[13]}$

\section{Sample Collection}

After completion of experimental study, according to CPSCEA guidelines all animals were anesthetize by using ketamine and blood was collected by retriorbital puncture. Now blood samples were centrifuged for $15 \mathrm{~m}$ at $10000 \mathrm{rpm}$ at $37^{\circ} \mathrm{C}$ collect serum and used for estimation of cytokines.

\section{Cytokines Assay}

Cytokines like IL- 6 , TNF $-\alpha$ and IL-10 (pg/ml) were estimated by using cytokines ELISA kits and assays were conducted as per ELISA kits manufacturer's guidelines. ${ }^{[14]}$

\section{Molecular Docking \\ Compounds from Biophytum veldkampii}

The following phytochemicals like 2, 6,3'4'-Tetrahydroxy-2-benzylcoumaranone, 2(1H)-Quinazolinone, 2(1H)-Quinazolinone, Phenylephrine, 4-_fluro_histamine, Phthalic_acid, Tenamfetamine, 3-Hydroxy-4-methoxybenzoic_acid, 3-Methoxyamphetamine, Phytol, n-Hexadecanoic_ acid and 9,12-Octadecadienoic_acid_(Z,Z) were subjected to docking studies. The structures and the physiochemical properties of these compounds were taken from the PubChem database (www. ncbi. nlm. nih.gov/pubchem.) $)^{[15]}$

COX-2 enzyme protein structure: The three-dimensional (3D) structure of the COX-2 enzyme was taken from the Protein Data Bank (PDB) database (www.rcsb.pdb) The PDB acts as a repository for the 3D structural data of large biological macromolecules such as proteins and nucleic acids. The PDB ID of COX- 2 enzyme is (PDB ID: 3LN1).

Docking studies: The docking studies of compounds were carried out using Auto dock 4.0 and Discovery studio Biovia 2017 software to find out the interaction between ligands and the target protein. ${ }^{[16,17]}$

\section{ADMET Analysis}

By using of admetSAR, ADMET properties of ligands were studied it is very important to know the pharmacokinetic properties of ligands to establish their function inside of the body. ${ }^{[18]}$

\section{Statistical analysis}

All the data were expressed as mean \pm S.D and performed by using one- way analysis of variance followed by Tukey test. $p<0.05$ is considered as statistically significant. 
Table 1: Phytochemicals present in methanolic extract of Biophytum veldkampii

\begin{tabular}{ccc}
\hline S.NO & Phytochemical tests & MEBV \\
\hline 1 & Alkaloids & - \\
2 & Glycosides & ++ \\
3 & Tannins & ++ \\
4 & Phenols & ++ \\
5 & Flavonoids & ++ \\
6 & Saponins & - \\
7 & Steroids & ++ \\
\hline
\end{tabular}

Where (+) Indicates presence, and (-) Indicates absence

Table 2: Effect of MEBV on COX II inhibition.

\begin{tabular}{cc}
\hline Group & Inhibition of COX II (\%) \\
\hline Group I Normal control & - \\
Group II: Carageenan control & - \\
Group III: Standard Diclofenac & 86.3 \\
Group IV MEBV & 78.3 \\
Group V MEBV & 60.34 \\
\hline
\end{tabular}

\section{RESULTS}

Phytochemical studies of methanolic extract revealed the presence of various phytochemicals shown in Table 1.

\section{Effect of MEBV on COX II inhibition}

The result of COX II inhibition by using methanolic extract of Biophytum veldkampii are summarized in Table 2 . The average COX II inhibition was calculated by taking the mean values. Diclofenac show $86.3 \%$ of COX II inhibition, Whereas MEBV at dose of $200 \mathrm{mg} / \mathrm{kg}$ exhibit $60.34 \%$ and at dose of $400 \mathrm{mg} / \mathrm{kg}$ show $78.3 \%$ inhibition of COX II.

\section{Effect of Biophytum veldkampii on paw thickness of rats $(\mathrm{cm})$ on Carageenan induced inflammation}

Injection of carageenan into the hind paws a progressive edema reaching it maximum at $5 \mathrm{hr}$. In case of Group I animals had shown (Normal control) paw thickness was found $3.028 \pm 0.12$ at $0 \mathrm{hr}$ and this remains constant up to $24 \mathrm{hr}$. Group II animals (Carageenan induced group) had showed an increase in a paw thickness for each hr, at $0 \mathrm{hr} .028 \pm 0.12 \mathrm{~cm}$, at $5 \mathrm{hr} 3.59 \pm 0.56 \mathrm{~cm}$, and at $24 \mathrm{hr} 4.01 \pm 0.18 \mathrm{~cm}$. The paw thickness of Group III (Diclofenac) animals was $3.35 \pm 0.41 \mathrm{~cm}$ which showed a mild increase at end of $3 \mathrm{hr}$, after end of $3 \mathrm{hr}$ it decreased the paw thickness to $3.04 \pm 0.58 \mathrm{~cm}$ and $2.99 \pm 0.74 \mathrm{~cm}$ at the end of 5 and $24 \mathrm{hr}$ respectively. Group IV (MEBV $400 \mathrm{mg} / \mathrm{kg}$ ) shows decreases the paw thickness to $3.014 \pm 0 \mathrm{~cm}$ at the end of $24 \mathrm{hr}$. Group V (MEBV $400 \mathrm{mg} / \mathrm{kg}$ ) show decreases the thickness of paw to $3.42 \pm 0.75 \mathrm{~cm}$ at the end of $24 \mathrm{hr}$. Figure 1

\section{Effect of Biophytum veldkampii on paw thickness of rats $(\mathrm{cm})$ on Formalin induced inflammation}

Injection of formalin into the hind paws a progressive edema reaching it maximum at $5 \mathrm{hr}$. In case of Group I animals had shown (Normal control) paw thickness was found $3.028 \pm 0.12$ at $0 \mathrm{hr}$ and this remains constant up to $24 \mathrm{hr}$. Group II animals (Formalin induced group) had showed an increase in a paw thickness for each hour, at $0 \mathrm{hr} 3.028 \pm$ $0.12 \mathrm{~cm}$, at $5 \mathrm{hr} 3.12 \pm 0.08 \mathrm{~cm}$, and $3.89 \pm 0.58^{\star *} \mathrm{~cm}$ at $24 \mathrm{hr}$. The paw thickness of Group III (Diclofenac) animals was $3.66 \pm 0.89 \mathrm{~cm}$ which
Effect of Biophytum veldkampii on paw thickness of rats $(\mathrm{cm})$ on Carageenan induced inflammation

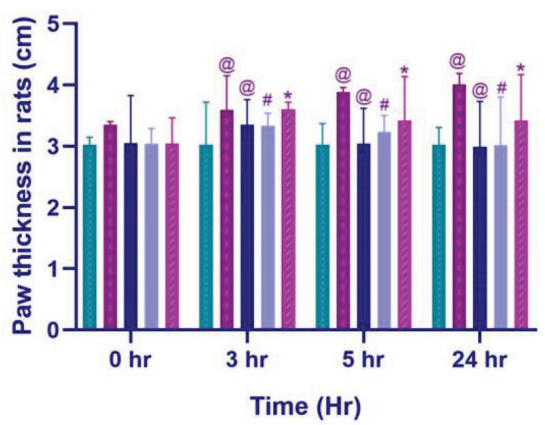

- Normal Control

- Carrageenan Control

Diclofenac

ㅍ. MEBV $(400 \mathrm{mg} / \mathrm{kg})$

MEBV $(200 \mathrm{mg} / \mathrm{kg})$

Figure 1: Effect of Biophytum veldkampii on paw thickness of rats $(\mathrm{cm})$ on Carageenan induced inflammation. All values are expressed as mean \pm S.D. @, $p<0.0001$ vs Normal Control; $\%, p<0.01$ vs Normal Control; \#, $p<0.05$ vs Normal Control; ${ }^{* *}, p<0.01$ vs Carageenan Control, ${ }^{*}, p<0.05$ vs Carageenan Control.

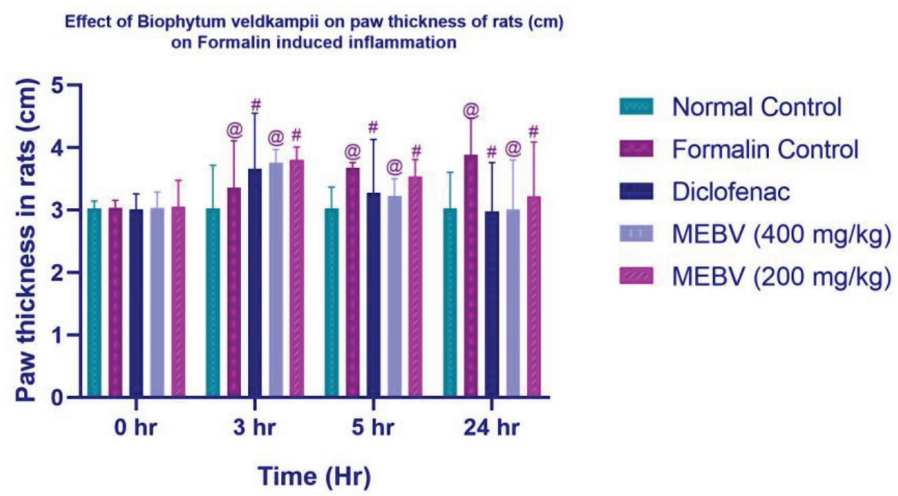

Figure 1: Effect of Biophytum veldkampii on paw thickness of rats $(\mathrm{cm})$ on Carageenan induced inflammation. All values are expressed as mean \pm S.D. @, $p<0.0001$ vs Normal Control; $\%, p<0.01$ vs Normal Control; \#, $p<0.05$ vs Normal Control; ${ }^{* *}, p<0.01$ vs Carageenan Control, ${ }^{*}, p<0.05$ vs Carageenan Control.

showed a mild increase at end of $3 \mathrm{hr}$, after end of $3 \mathrm{hr}$ it decreased the paw thickness to $3.28 \pm 0.85 \mathrm{~cm}$ and $2.98 \pm 0.78 \mathrm{~cm}$ at the end of 5 and 24 hr respectively. Group IV (MEBV $400 \mathrm{mg} / \mathrm{kg}$ ) shows decreases the paw thickness to $3.014 \pm 0.79 \mathrm{~cm}$ at the end of $24 \mathrm{hr}$. Group V (MEBV 200 $\mathrm{mg} / \mathrm{kg}$ ) show decreases the thickness of paw to $3.22 \pm 0.87 \mathrm{~cm}$ at the end of $24 \mathrm{hr}$. Figure 2

\section{Effect of Biophytum veldkampii on motility of rats}

Walking ability of the rats to climb the staircase at the time of peak inflammation was checked by score of motility. Group I (normal control) animals showing the motility score is 2 . Group II (carageenan) animals show $0.16 \pm 0.35$ motility score. Whereas Group IV (MEBV $400 \mathrm{mg} / \mathrm{kg}$ ) and V (MEBV $200 \mathrm{mg} / \mathrm{kg}$ ) animals exhibits motility score like $1.58 \pm 0.78$ and $1.22 \pm 0.48$ respectively. This indicates MEBV decrease the inflammation and increase the walking ability of animals.

\section{Effect of Biophytum veldkampii on cytokines expression $(\mathrm{pg} / \mathrm{ml})$}

In Group II (Carageenan treated animals) shows highest levels of serum IL-6 $(82.4 \pm 1.25 \mathrm{pg} / \mathrm{ml})$, TNF- $\alpha(779 \pm 0.68 \mathrm{pg} / \mathrm{ml})$ and lowest values of IL-10 (18.4 $\pm 089 \mathrm{pg} / \mathrm{ml})$ compared to normal group. On the contrary, Diclofenac sodium treated animals show statistically decreased the IL-6 
Effect of Biophytum veldkampii on paw thickness of rats (cm) on Formalin induced inflammation

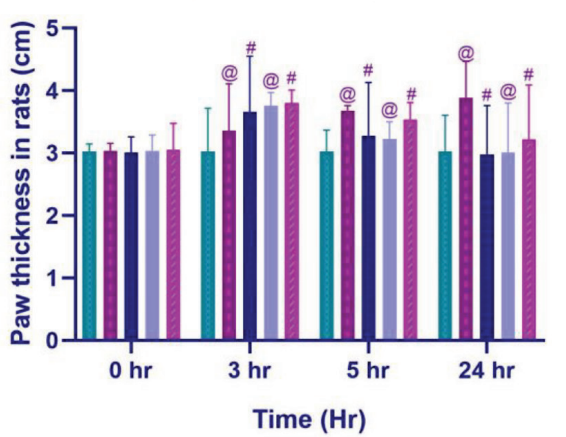

Figure 2: Effect of Biophytum veldkampii on paw thickness of rats $(\mathrm{cm})$ on Formalin induced inflammation. All values are expressed as mean \pm S.D. @, $p<0.0001$ vs Normal Control; $\%, p<0.01$ vs Normal Control; \#, $p<0.05$ vs Normal Control; ${ }^{* *}, p<0.01$ vs Carrageenan Control, *,$p<0.05$ vs Carrageenan Control.

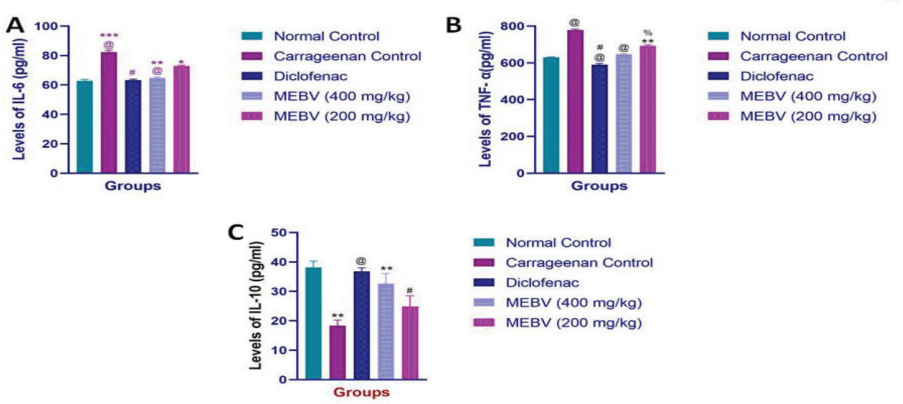

Figure 3: Effect of Biophytum veldkampii on cytokines expression (pg/ml). All values are expressed as mean \pm S.D. @, $p<0.0001$ vs Normal Control; $\%, p<0.01$ vs Normal Control; $\#, p<0.05$ vs Normal Control; ${ }^{* *}, p<0.01$ vs Carageenan Control, ${ }^{*}, p<0.05$ vs Carageenan Control.

and TNF- $\alpha$ and increases levels of IL-10. Whereas Biophytum veldkampii treated groups like Group IV(MEBV 400mg/kg) and Group V (MEBV $200 \mathrm{mg} / \mathrm{kg})$ exhibits low levels of IL-6 $(64.8 \pm 0.69 \mathrm{pg} / \mathrm{ml} ; 72.8 \pm 0.62 \mathrm{pg} / \mathrm{ml})$ and TNF- $\alpha(646 \pm 2.75 \mathrm{pg} / \mathrm{ml} ; 692 \pm 0.36 \mathrm{pg} / \mathrm{ml})$ and elevated levels of IL-10 $(32.6 \pm 0.85 \mathrm{pg} / \mathrm{ml} ; 24.9 \pm 0.63 \mathrm{pg} / \mathrm{ml})$. Figure 3

\section{Computational Study}

In silico studies of compounds present in Biophytum veldkampii, using Auto Dock 4.0 showed the following results. Of 11 compounds studied, 2, 6, 3', 4'-Tetrahydroxy-2-benzylcoumaranone, 2(1H)-Quinazolinone satisfy the Lipinski's rule of five for drug-likeness. The other compounds which do not follow the Lipinski's properties were not considered for further docking studies. The structures of compounds from Biophytum veldkampii are shown in Figure 4. The binding energy for each chosen compound with the COX-2 enzyme is given in Table 3.

The amino acid residues at active site of COX-2 are cysteine, tyrosine, proline, aspargine, arginine, lucine and glycine. Docking studies show that the ligands bind to the active site region of COX-2 enzyme with good binding energy in the same Diclofenac hydrophobic pocket. The docking models of the selected compounds (1) Diclofenac, (2) 2, 6,3',' '-Tetrahydroxy-2-benzylcoumaranone, 2(1H)-Quinazolinone in 3D view are shown in Figure 2-4. The hydrogen contacts of the ligands are given in Table 2. Docking researches revealed that 2, 6,3',' -Tetrahydroxy-2-benzylcoumaranone had the most excellent docking rating of $-6.8(\mathrm{Kcal} /$ mol)which showed three hydrogen bond interactions (CYS A:32 (2.67),

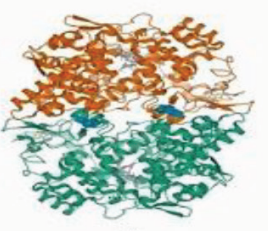

A.

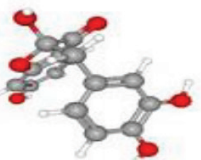

$\mathbf{C}$

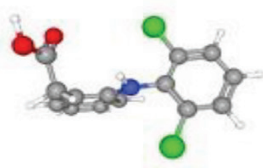

B.

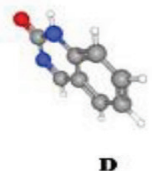

Figure 4: The Three Dimensional structures of target and ligands. (a) Cyclooxygenase -II (PDB ID: 3LN1), (b) Diclofenac sodium (c) 2, 6, 3', 4'-Tetrahydroxy-2-benzylcoumaranone (d) 2(1H)-Quinazolinone.

Table 3: Binding affinities of isolated compounds at the active site of COX II.

\begin{tabular}{|c|c|c|}
\hline \multirow[t]{2}{*}{ Sr. No } & \multirow[t]{2}{*}{ Ligands } & $\begin{array}{c}\text { Dock Score (Kcal/ } \\
\text { mol) }\end{array}$ \\
\hline & & 3LN1 \\
\hline 1 & Diclofenac & -6.9 \\
\hline 2 & $\begin{array}{c}\text { 2,6,3'4'-Tetrahydroxy-2- } \\
\text { benzylcoumaranone }\end{array}$ & -6.8 \\
\hline 3 & 2(1H)-Quinazolinone & -6.2 \\
\hline 4 & Phenylephrine & -5.8 \\
\hline 5 & 4-_fluro_histamine & -5.7 \\
\hline 6 & Phthalic_acid & -5.7 \\
\hline 7 & Tenamfetamine & -5.7 \\
\hline 8 & 3-Hydroxy-4-methoxybenzoic_acid & -5.5 \\
\hline 9 & 3-Methoxyamphetamine & -5.5 \\
\hline 10 & Phytol & -5.5 \\
\hline 11 & n-Hexadecanoic_acid & -5.1 \\
\hline 12 & 9,12-Octadecadienoic_acid_(Z,Z) & -4.8 \\
\hline
\end{tabular}

TYR A:116 (5.81)), hydrophobic interactions (PRO A:139 (4.95)) and also electrostatic interaction (ASP A:111 (7.25), ARG A:29 (4.05), GLU A:31 (4.90)) with COX-II enzyme, where as $2(1 \mathrm{H})$-Quinazolinone also show good docking rating of -6.2 , which showed three hydrogen bond interactions (ASN A:24 (3.22), GLN A:447 (5.37)), hydrophobic interactions (ARG A:455 (4.85), ARG A:29 (5.70), LEU A:138 (6.04)) with amino acids of COX-2.The standard Diclofenac revealed the highest possible docking rating of $-6.9(\mathrm{Kcal} / \mathrm{mol})$. The outcomes gotten by the auto dock 4.0 are shown in Table 2, as well as the protein-ligand interactions revealing hydrogen bonding and also binding settings are additionally published in Tables 3 (Figure 5-7).

\section{ADME/T evaluation by using admetSAR}

In this research by using admetSAR, ADMET properties of ligand were estimated. All ligands shows excellent human intestinal solubility, Blood brain barrier infiltration (BBB).All ligands were AMES negative. The 
Table 4: Interactions COX II amino acid residues with ligands at receptor site.

\begin{tabular}{|c|c|c|c|c|}
\hline \multirow[b]{2}{*}{ Ligands } & \multirow{2}{*}{$\begin{array}{l}\text { Binding } \\
\text { Affinity, } \Delta \mathrm{G} \\
\text { (Kcal/mol) }\end{array}$} & \multicolumn{3}{|c|}{ Amino acids involved and Distance $\left(A^{\circ}\right)$} \\
\hline & & $\begin{array}{l}\text { Hydrogen Binding } \\
\text { Interactions }\end{array}$ & Hydrophobic Interactions & Electrostatic Interactions \\
\hline Diclofenac & -6.9 & GLY A:30 (4.35) & $\begin{array}{c}\text { PRO A:139 (4.97, 6.15), CYS A:32 (4.88), } \\
\text { LEU A:138 (5.20), ARG A:29 (4.29), ARG } \\
\text { A:455 (4.16) }\end{array}$ & - \\
\hline $\begin{array}{l}2,6,3^{\prime}, 4^{\prime} \text {-Tetrahydroxy-2- } \\
\text { benzylcoumaranone }\end{array}$ & -6.8 & $\begin{array}{c}\text { CYS A:32 (2.67), TYR A:116 } \\
\text { (5.81) }\end{array}$ & PRO A:139 (4.95) & $\begin{array}{l}\text { ASP A:111 (7.25), ARG A:29 } \\
\text { (4.05), GLU A:31 (4.90) }\end{array}$ \\
\hline 2(1H)-Quinazolinone & -6.2 & $\begin{array}{c}\text { ASN A:24 (3.22), GLN A:447 } \\
(5.37)\end{array}$ & $\begin{array}{c}\text { ARG A:455 (4.85), ARG A:29 (5.70), LEU } \\
\text { A:138 (6.04), GLU A:451 (4.64) }\end{array}$ & - \\
\hline
\end{tabular}

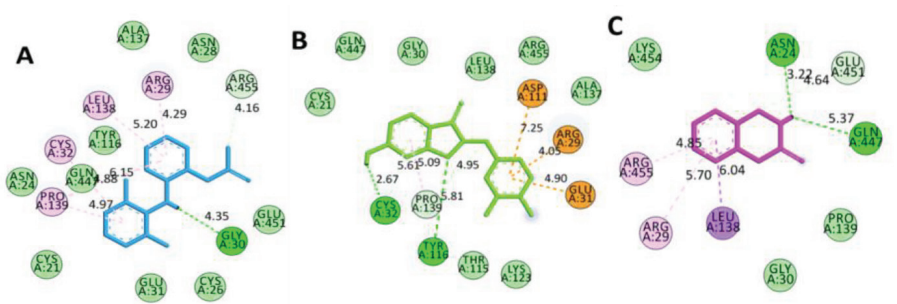

Figure 5: 2D Interactions of ligands with Cyclooxygenase -II (PDB ID: 3LN1) (A) Diclofenac (B) 2, 6, 3', 4'-Tetrahydroxy-2-benzylcoumaranone(C) 2(1H)Quinazolinone

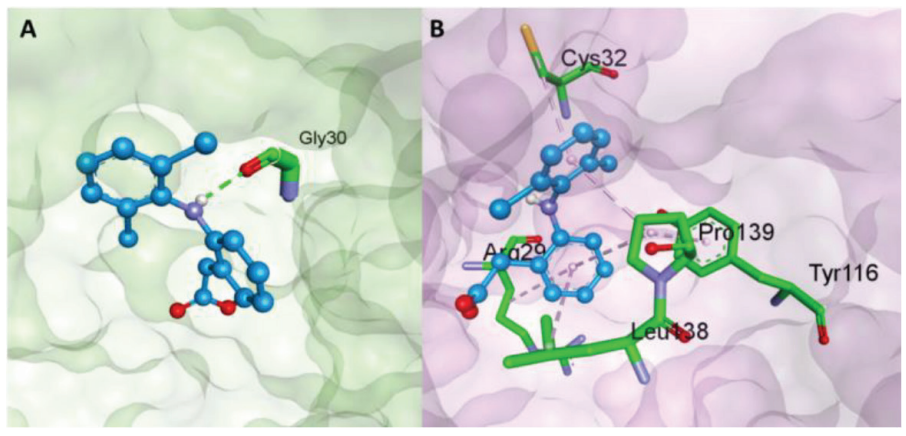

Figure 6: 3D Interactions of Diclofenac with COX-II (PDB ID: 3LN1) (A) Hydrogen Bonding (B) Hydrophobic Interactions.

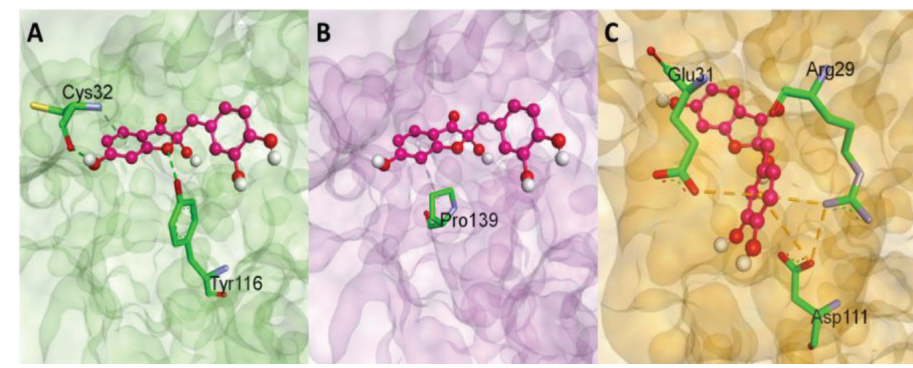

Figure 7:3D interactions of 2,6, 3', 4'-Tetrahydroxy-2-benzylcoumaranone with COX-2 (PDB IS: 3LN1) (A) Hydrogen Bonding (B) Hydrophobic Interactions and (C) Electrostatic Interactions.

results of HIA, BBB and LD50 values of the ligands are shown in Table 4 and 5.

\section{DISCUSSION}

For screening of anti- inflammatory activity of drugs, carageenan induced rat paw edema model is suitable and commonly used method.
Table 5: ADME/T properties of different compounds from Biophytum veldkampii.

\begin{tabular}{|c|c|c|c|c|c|}
\hline 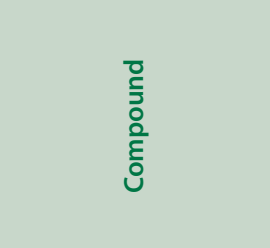 & 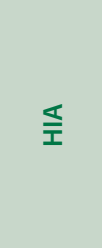 & $\stackrel{\mathscr{0}}{\infty}$ & 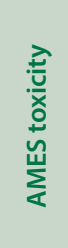 & 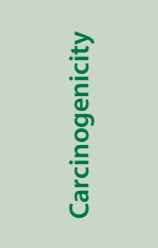 & 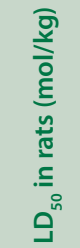 \\
\hline Diclofenac & 0.99455 & 0.9481 & $\begin{array}{l}\text { Non } \\
\text { toxic }\end{array}$ & $\begin{array}{c}\text { Non } \\
\text { carcinogenic }\end{array}$ & 2.085 \\
\hline $\begin{array}{l}\text {,6, 3', 4'-Tetrahydroxy- } \\
\text { 2-benzylcoumaranone }\end{array}$ & 0.9648 & 0.8245 & $\begin{array}{l}\text { Non } \\
\text { toxic }\end{array}$ & $\begin{array}{c}\text { Non } \\
\text { carcinogenic }\end{array}$ & 1.4228 \\
\hline 2(1H)-Quinazolinone & 0.9786 & 0.9246 & $\begin{array}{l}\text { Non } \\
\text { toxic }\end{array}$ & $\begin{array}{c}\text { Non } \\
\text { carcinogenic }\end{array}$ & 1.8246 \\
\hline
\end{tabular}

Carageenan is a polysaccharide it cause the inflammation by release of pro inflammatory mediators like prostaglandins, leuckotrienes, histamine and TNF alpha. ${ }^{[19]}$ The inflammation occurs in two phase. In first phase started with release of histamine, 5HT and kinins after the injection of carageenan in the first few hours. In second phase related to release of prostaglandins in next 2-3 hr. Prostaglandins are main chemical agents responsible for inflammation. Second phase is the most target phase for steroidal and non-steroidal anti-inflammatory drugs. ${ }^{[20]}$

In this research Biophytum veldkampii had very consistent anti-inflammatory action and exhibit significant decreases thickness of paw. Although, the Cyclooxygenase and lipoxygenases pathways play a vital role in the inflammatory process, the inhibition of Cyclooxygenase is more effective in inhibiting carageenan-induced inflammation than lipoxygenases inhibitors. ${ }^{[21]}$

Biophytum veldkampii might have inhibited the synthesis of PGs mediated by Cyclooxygenase. Oral administration of methanolic extract of Biophytum veldkampii significantly decreases the pro inflammatory cytokines and elevated the anti-inflammatory cytokines. COX enzyme increases the prostaglandins synthesis which causes the decreases the antiinflammatory cytokines like IL-10, IL-4 and IL-13. Our present findings Biophytum veldkampii shows elevated levels of IL-10 hence IL-10 has been found as a potent macrophage deactivator, which blocked TNF- $\alpha$, IL-1, IL-6, IL-8, and GM-CSF by human monocytes. ${ }^{[22]}$

In silico molecular docking studies is one of the significant method to development of new medications for various pathological conditions, advantage of this method is less time and required less budget compared to standard lab experiments.

In this research, we used a docking method making use of open software programs as well as virtualized. Interactions of ligands 2, 6, 3', 4'-Tet- 
rahydroxy-2-benzylcoumaranone and 2(1H)-Quinazolinone with anti-inflammatory protein COX-II enzyme. $\Delta \mathrm{G}$ indicates informative of ligand docking in the active site of a protein, kind of molecular communications, such as hydrogen bond, hydrophobic, as well as likewise electrostatic interactions, with necessary amino acid, which is a step of ligand docking in favorable conformations. Hydrophobic synergy is the main aspect of the firmness of proteins. Hydrogen bonding furthermore maintains protein firmness, yet to a minimized degree than hydrophobic synergy. Our results disclose that electrostatic, hydrophobic and hydrophilic communications are regulated by numerous amino acid deposits in each ligand-protein communication.

2,6,3'4'-Tetrahydroxy-2-benzylcoumaranone exhibits hydrogen bond, hydrophobic bond and electrostatic interactions whereas $2(1 \mathrm{H})$ Quinazolinone exhibits only hydrogen bond, and hydrophobic bond interactions.

\section{CONCLUSION}

To conclude with the compounds from the Biophytum veldkampii showed better binding features with the COX-2 enzyme. Thus, these compounds can be effectively used as drugs for treating inflammation which is predicted on the basis of docking scores. The insights gained in this work can be further used in experimental studies for designing anti-inflammatory drugs with novel targets and mechanism of action.

\section{ACKNOWLEDGEMENT}

All authors are thankful to management of K L College of Pharmacy, vaddesweram, Guntur and Shri Vishnu College of Pharmacy to provide faculties to conduct in-vivo studies.

\section{CONFLICT OF INTEREST}

The authors declare no conflict of interest.

\section{ABBREVIATIONS}

HIA: Human Intestinal Absorption; B.B.B.: Blood- Brain Barrier; LD $_{50}$ : Lethal Dose 50\%; MEBV: Methanolic extract of Biophytum veldkampii.

\section{REFERENCES}

1. Pierangeli G, Vital G, Rivera W. Antimicrobial activity and cytotoxicity of Chromolaena odorata (L. f) King and Robinson and Uncaria perrottetii (A. Rich) Merr. extracts. J Med Plants Res. 2009;3:511-8.

2. Chajjed SS, Hiwani PB, Bastikar VA, Upasani CD, Udavant PB, Dhake AS, et al. Structure based design and in-silico molecular docking analysis of some novel benzamidazoles. Int J Chem Tech Res. 2010;2:1135-140.

3. Seibert K, Masferrer JL. Role ofinducible cyclooxygenase (COX-2) in inflammation. Receptor. 1994;4(1):17-23. PMID 8038702.

4. Minghetti Luisa. Cyclooxygenase-2 (COX-2) in inflammatory and degenerative brain diseases. J Neuropathol Exp Neurol. 2004;63(9, September):901-10. doi: 10.1093/jnen/63.9.901, PMID 15453089

5. Vane JR. Inhibition of prostaglandin synthesis as a mechanism of action for aspirin-like drugs. Nat New Biol. 1971;231(25):232-35. doi: 10.1038/newbio231232a0, PMID 5284360.

6. Sadasivan Sreeshma L, Nair Bindu Rajeswary. GC-MS analysis in two species of Biophytum DC. J Pharm Res. 2014;8(4):466-73.

7. sudharsan Setti meenambiga. Kalyanaraman Rajagopal, Durga R. In silico docking studies on the components of Inonotus sp., a medicinal mushroom against cyclooxygenase-2 enzyme. Asian J Pharm Clin Res. 2015;8(3):142-5.

8. Bandaru Nagaraju, Ramu A, Vidhyadhara S. Neuroprotective and antioxidant activities of fraction isolated from methanolic extract of Sapindus laurifolia on scopolamine induced dementia.Phocg. Res. 2020;12:119-26.

9. Thilagavathi. T, Arvindganth.R, Vidhya.D, Dhivya. R Preliminary Phytochemical screening of different solvent mediated medicinal plant extracts evaluated. Int Res J Pharm. 2015;6(4).

10. Shaikh Rafik U, Pund Mahesh M, Gacche Rajesh N. Evaluation of anti-inflammatory activity of selected medicinal plants used in Indian traditional medication system in vitro as well as in vivo. J Tradit Complement Med. 2016 October;6(4):355-61. doi: 10.1016/j.jtcme.2015.07.001, PMID 27774419.

11. Jyothirmai N, Nagaraju B. M. Yaso deepika, J.N.Suresh Kumar, G.Swarupa rani. Evaluation of Anti-Inflammatory and anti-bacterial Activities of different solvent extracts of Ehretia laevis Roxb. J Pharm Sci Res. 2016;8(8):715-20.

12. Sharma Vikas Chandra, Kaushik Atul, Dey Yadu Nandan, Srivastava Bhavana, Wanjari Manish, Jaiswal Bhagat. Analgesic, anti-inflammatory and antipyretic activities of ethanolic extract of stem bark of Anogeissus latifolia Roxb. Clin Phytosci. 2020;6(1):22. doi: 10.1186/s40816-020-00171-2.

13. De Castro Costa Mauricio, De Sutter Paul, Gybels Jan, Van Hees Johan Adjuvant-induced arthritis in rats: a possible animal model of chronic pain. Pain. 1981;10(2):173-85. doi: 10.1016/0304-3959(81)90193-7, PMID 7267134.

14. Rizvi Waseem, Fayazuddin Mohd, Shariq Syed, Singh Ompal, Moin Shagufta, Akhtar Kafil, Kumar Anil. Anti-inflammatory activity of roots of Cichorium intybus due to its inhibitory effect on various cytokines and antioxidant activity. ancient life sciences. 2014;34:44-9.

15. Manna MK. Oxalidaceae (Biophytum DC.), flora of India, (Malpighiaceae-Dichapetalaceae). Calcutta, India, botanical survey of India Hajra PK, Nair VJ, Daniel P, editors. Vol. 4; 1997. p. 231-55.

16. Bala Dintakurthi Sree Naga, Prasanth Krishna, Panda Siva Prasad, Lakshmana Rao Atmakuri, Teja Nayudu, Vani Veenam Bhavya Naga, Sandhya Tera, Rao Pathange Bharghava Bhushan. In vitro Anthelmintic Impact of Various Extracts of Pavetta tomentosa Root on Pheretima posthuma and in-silico Molecular Docking Evaluation of some Isolated phytoconstituents. Indian J Pharm Educ Res. 2020;54:2-6.

17. Morris Garrett M, Huey Ruth, Lindstrom William, Sanner Michel F, Belew Richard K, Goodsell David S, Olson Arthur J. Auto Dock 4 and Auto Dock Tools 4: automated docking with selective receptor flexibility. J Comput Chem. 2009;30(16):2785-91. doi: 10.1002/jcc.21256, PMID 19399780.

18. Lim SV, Rahman MB, Tejo BA. Structure-based and ligand-based virtual Screening of novel methyltransferase inhibitors of the dengue virus. BMC Bioinformatics: bio Med Central. Vol. 12(13). Suppl 24; 2011.

19. Bhukya B, Anreddy RNR, William CM, Gottumukkala KM. Analgesic and anti-inflammatory activities of leaf extract of Kydia calycina Roxb. Bangladesh J Pharmacol. 2009;4(2):101-4. doi: 10.3329/bjp.v4i2.2112

20. Brooks PM, Day RO. Nonsteroidal antiinflammatory drugs--differences and similarities. N Engl J Med. 1991;324(24):1716-25. doi: 10.1056/ NEJM199106133242407, PMID 2034249.

21. Giuliano Francesco, WarnerTimothy D. Origins of prostaglandin E2: involvements of cyclooxygenase (COX)-1 and COX-2 in human and rat systems. J Pharmacol Exp Ther. 2002;303(3):1001-6. doi: 10.1124/jpet.102.041244, PMID 12438520.

22. Trushin Sergey A, Pennington Kevin N, Carmona Eva M, Asin Susana, Savoy Doris N, Billadeau Daniel D, Paya Carlos V. Protein kinase Calpha (PKCalpha) acts upstream of PKCtheta to activate IkappaB kinase and NF-kappaB in T lymphocytes. Mol Cell Biol. 2003;23(19):7068-81. doi: 10.1128/ MCB.23.19.7068-7081.2003, PMID 12972622. 
GRAPHICAL ABSTRACT
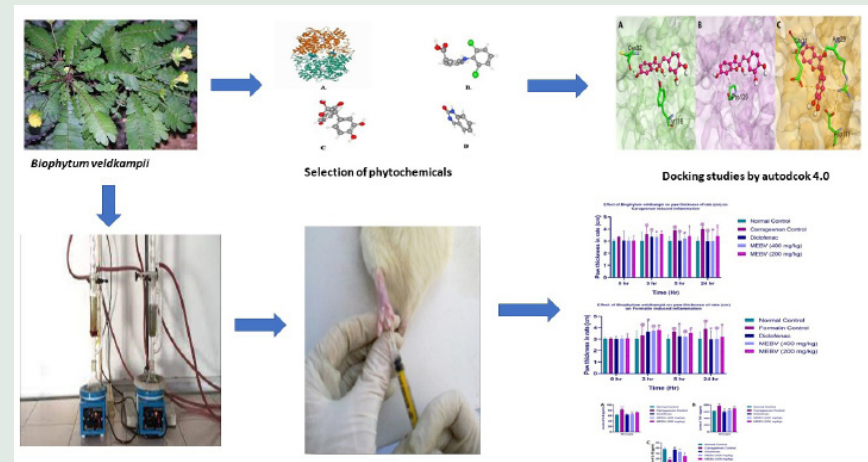

Preparation of extract
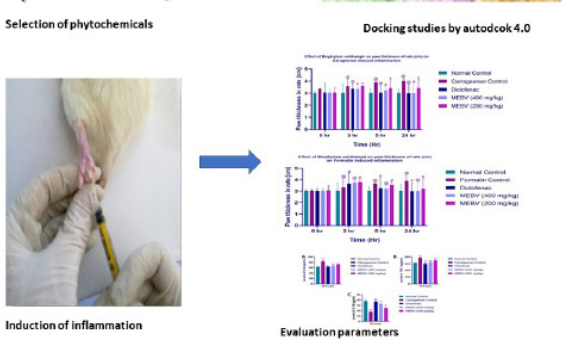

\section{SUMMARY}

In this research Biophytum veldkampii was subjected to extraction using methanol. In-vivo anti-inflammatory activity was assessed by using carageenan induced inflammation on rats and in-silico molecular docking studies was performed by using of Autodock 4.0. The outcomes revealed that the methanolic extract has most prominenant anti-inflammatory activity at various doses. Among all the substances 2,6,3',4'-Tetrahydroxy-2-benzylcoumara none revealed the most effective docking rating of -6.8 , which is near to Diclofenac, i.e. - 6.9, ensuring that 2,6,3',' '-Tetrahydroxy-2-benzylcoumaranone has a strong binding fondness in between protein and ligand. From the results, a conclusion can be drawn that the anti-inflammatory activity of Biophytum veldkampii in both in vivo and in silico methods. This information sustains 2,6,3',4'-Tetrahydroxy-2-benzylcoumaranone to be a useful anti inflammatory compound beneficial to future clinical studies.

\section{ABOUT AUTHORS}

Nagaraju Bandaru completed his Ph.D in Department of Pharmacology, presently he working as Assistant Professor at K L University. He published more than 50 articles in various reputed journals, he also published 3 book chapters and he got patent publication recently.

Cite this article: Bandaru N, Prasanth DSNBK, Reddy AR, Rao SNK, Nemmani KVS. In-silico Molecular Docking Studies of some Isolated Phytochemicals from Biophytum veldkampii against Cyclooxygenase-II Enzyme and in vivo Anti-inflammatory Activity. Pharmacog Res. 2021;13(4):192-8. 